\title{
Prevalence of Dental Caries among Elementary School Girls in Riyadh, Kingdom of Saudi Arabia: A Cross-sectional Survey
}

\author{
${ }^{1}$ Sattam A Alshiha, ${ }^{2}$ Hessa M Alwayli, ${ }^{3}$ Mohammed A Hattan, ${ }^{4}$ Yazeed K Alfraih \\ ${ }^{5}$ Abdullah A Alamri, ${ }^{6}$ Mohammed S Aldossary
}

\begin{abstract}
Aim: To assess caries prevalence among 6- to 9-year-old female children in Riyadh, Kingdom of Saudi Arabia and compare between results based on nationality and age levels.

Materials and methods: A total of 17,891 female students from 120 public female elementary schools in Riyadh city were examined according to the World Health Organization (WHO) diagnostic criteria. The decayed [dt], missing due to caries [mt], and filled [ft] primary teeth ( $\mathrm{dmft}$ ) index and its components were measured. One-way analysis of variance (ANOVA), Student's t-test, and Chi-squared test were used to determine the significance differences, at $\alpha=0.05$.
\end{abstract}

Results: The overall mean [dt] for all children was 3.89 [standard deviation (SD) 3.38], which increased to 5.0 (SD 3.02) when excluding children without active caries. The mean $\mathrm{dmft}$ was 5.69 (SD 4.0). However, excluding children with $\mathrm{dmft}=0$, the mean dmft was raised to 6.41 (SD 3.65). The caries prevalence was $88.82 \%$. The non-Saudi children showed slightly higher values compared with Saudi children. However, statistically, there were only significant differences in values of [dt] mean, $\mathrm{dt}=0$, and $[\mathrm{ft}]$ mean $(\mathrm{p}<0.05)$. The $\mathrm{dmft}$ index was higher for 7- to 8-year-old group (5.81, SD 3.98) followed by the 8- to 9-year-old group (5.79, SD 3.79) and the 6- to 7-yearold group (5.47, SD 4.18). However, there were no statistically significant differences $(p>0.05)$ between 7 - to 8-year-old and 8- to 9-year-old children. The 6- to 7-year-old children were statistically different from the 7- to 8 and 8- to 9-year-old children.

Conclusion: The dental caries prevalence among the study population was high, with the majority of children having untreated caries. This highlights the need for initiating deliberate community-based preventive measures for improvement in public health education and services provided.

Keywords: Caries prevalence, Cross-sectional survey, Dental caries, Dental health, Oral health, Schoolchildren.

How to cite this article: Alshiha SA, Alwayli HM, Hattan MA, Alfraih YK, Alamri AA, Aldossary MS. Prevalence of Dental Caries among Elementary School Girls in Riyadh, Kingdom of Saudi Arabia: A Cross-sectional Survey. J Oral Health Comm Dent 2017;11(2):29-33.

\footnotetext{
${ }^{1,2,5}$ Consultant, ${ }^{3,6}$ Specialist, ${ }^{4}$ General Dentist

${ }^{1-6}$ Dental Department, Ministry of Health, Riyadh, Kingdom of Saudi Arabia

Corresponding Author: Mohammed S Aldossary, P.O. Box 13743, Riyadh, Kingdom of Saudi Arabia, Phone: +00966504111910, e-mail: msfd99@hotmail.com
}

Source of support: The study was funded by the Ministry of Health, Riyadh, Kingdom of Saudi Arabia

Conflict of interest: None

\section{INTRODUCTION}

Dental caries is considered as a major public health problem among children worldwide. It is the most prevalent disease among children and one of the most expensive diseases to treat. ${ }^{1,2}$ Epidemiological surveys are essential for monitoring dental caries trends and patterns, assessment of dental needs, and designing appropriate preventive oral health programs and programs aimed at improving oral health services in the community. ${ }^{3-5}$

The persistence of high caries prevalence in children in Kingdom of Saudi Arabia has been reported in the literature over many years both nationally and regionally, for different target groups. The surveys have been carried out as age-specific, or for preschoolchildren and schoolchildren, and some surveys have tried to determine caries association risk and preventive factors. ${ }^{6,7}$

Riyadh city is the capital and the largest city of the Kingdom of Saudi Arabia. Previous surveys have demonstrated a high caries prevalence among elementary schoolchildren in Riyadh. ${ }^{8-12}$ Since the last caries prevalence survey specifically for elementary schoolchildren in Riyadh was over 12 years ago, ${ }^{10,12}$ there seemed to be a need to conduct another study as follow-up on the previous studies to observe the changes in caries prevalence in this specific age group of 6- to 9-year-old children.

In addition, different governmental and private organizations in Kingdom of Kingdom of Saudi Arabia provide independently preventive programs, and it is worthy to follow-up and monitor the efficiency of the applied dental health education and preventive programs and dental services in general.

The present cross-sectional study aimed to:

- Report the dental caries prevalence in the primary dentition among 6- to 9-year-old public female elementary schoolchildren in Riyadh city, Kingdom of Saudi Arabia.

- Compare results by factors of nationality and age levels. 


\section{MATERIALS AND METHODS}

\section{Population and Sample Composition}

The present cross-sectional study was a part of the annual dental preventive program targeting elementary schoolchildren, organized and ethically approved by the Preventive Dentistry Department, Ministry of Health, Riyadh, Kingdom of Saudi Arabia. The program includes educational part on oral hygiene and topical fluoride application.

The survey was conducted during October 2015 to May 2016 at public female elementary schools in Riyadh city, Kingdom of Saudi Arabia. The total number of Riyadh public female elementary schools in the 2015 to 2016 academic year was 456 schools, with a total number of 185,809 female students. The Saudi female children counted for $142,243(76.6 \%)$ and the non-Saudi children were 43,561 $(23.4 \%)$ students. ${ }^{13}$ The non-Saudi children included other Arabic-speaking nationalities from the Middle East such as Yeminis, Palestinians, Egyptians, Sudanese, and Syrians.

The information about the population of elementary schoolchildren was obtained from the Ministry of Education $^{13}$ and served as sampling frame for the study. From the list provided, 120 public female elementary schools were randomly selected from different five areas within Riyadh City (North, East, West, South, and Central) using stratified random sampling. This sample was chosen to ensure appropriate sociodemographic representation.

The schools were officially informed, and visitation permissions and coordination with the schools were obtained from the Ministry of Education and school principals to arrange a day for data collection. Written consent was obtained from the children's parents.

A total of 17,891 female students were examined, which included all children with obtained consent form, aged 6 to 9 years within the selected school. Before commencing the examination, a brief orientation and oral hygiene instructions to the students were carried out. Topical fluoride varnish (Clinpro ${ }^{\mathrm{TM}} 5 \%$ sodium fluoride White Varnish, 3M ESPE, St. Paul, MN, USA) was applied following examination of the children with obtained informed consent.

\section{Screening}

Forty examiners, licensed registered female dental hygienists (trained and calibrated) conducted the oral examination. They were divided into 20 teams, and by this way, each team included two examiners; one either conducted examination or assisted in data entry in a designed data collection form.
The screening for dental caries was conducted according to the WHO criteria for diagnosing dental caries. ${ }^{14}$ The dmft index (primary teeth only) was used to assess the caries prevalence.

The children were examined in their classroom with the child sitting on a conventional, nondental classroom chair. The caries assessment was done visually with the aid of a disposable mouth mirror, tongue blade, and a probe, when needed, under adequate natural light, and under all infection control measures. The probe was used sparingly on doubtful surfaces. In case of any doubt, the tooth was marked sound. Tooth was recorded as missing due to caries [mt] if the tooth was not present at an age when normal exfoliation would not be a sufficient explanation for its absence. No radiographic examination was performed.

\section{Statistical Analysis}

Using Kappa statistics, inter- and intraexaminer reproducibility was assessed by reexamining a group of 120 children, 5 weeks after the start of the study. A very high degree of agreement was demonstrated (Kappa $>0.80$ ).

All data were entered in Microsoft ${ }^{\circledR}$ Excel $^{\circledR}$ (Microsoft ${ }^{\circledR}$ Office 2007, Microsoft ${ }^{\circledR}$ Corp, Redmond, WA, USA). All statistical analyses were performed using Statistical Package for the Social Sciences (IBM SPSS Statistics 20.0 Armonk, NY, USA). Frequencies, means, and standard deviation were generated.

One-way ANOVA and Student's $t$-test were used to determine statistical significance differences between means of results. Chi-squared test was used to assess the significance of differences in proportions.

Comparisons were made based on factors of nationality (Saudi, non-Saudi) and age groups (6-7, 7-8, 8-9 years). The level of statistical significance was set at $\alpha=0.05$.

\section{RESULTS}

This study consisted of 17,891 public elementary school girls aged 6 to 9 years, who were examined for dental caries from 120 schools in Riyadh city.

The detailed caries prevalence results of the whole participants are presented in Table 1. The overall mean [dt] for all children was 3.89 (SD 3.38), which increased to 5.0 (SD 3.02) when excluding children without active caries $(\mathrm{dt}=0 ; \mathrm{n}=3,959)$. The active caries-free children accounted for $22.13 \%$ of the examined children, which indicated that $77.87 \%$ of children were with active, untreated caries. The range of decayed teeth was 0 to 20 . There were only six children with $\mathrm{dt}=20$, four children were Saudi, and two children were non-Saudi. All the 
Table 1: Caries prevalence of all the participants $(n=17,891)$

\begin{tabular}{lll}
\hline The decayed & Range & $0-20$ \\
teeth [dt] & Mean (SD) & $3.89(3.38)$ \\
& Students with [dt] = 0 n (\%) & $3959(22.13 \%)$ \\
& Mean (SD); after excluding & $5.0(3.02)$ \\
& [dt] = 0 & \\
The missing & Range & $0-17$ \\
teeth due to & Mean (SD) & $1.41(2.21)$ \\
caries [mt] & Students with [mt] = 0 n (\%) & $8971(50.14 \%)$ \\
& Mean (SD); after excluding & $2.82(2.42)$ \\
& [mt] = 0 & $0-12$ \\
The filled & Range & $0.39(1.02)$ \\
teeth [ft] & Mean (SD) & $14,657(81.92 \%)$ \\
& Students with [ft] = 0 n (\%) & $2.17(1.38)$ \\
& Mean (SD); after excluding & \\
& [ft] = 0 & $0-20$ \\
The [dmft] & Range & $5.69(4.0)$ \\
index & Mean (SD) & $2001(11.18 \%)$ \\
& Students with [dmft] = 0 n (\%) & \\
& Mean (SD); after excluding & $6.41(3.65)$ \\
& [dmft] = 0 & \\
\hline
\end{tabular}

six children were in the 6- to 7-year-old age group. The mean of the missing teeth due to caries [mt] was 1.41 (SD 2.21), and the mean of the filled teeth [ft] was 0.39 (SD 1.02). Children with at least one filling accounted for $18.08 \%(\mathrm{n}=3,234)$.

The decayed teeth [dt] component was the major constituent of the $\mathrm{dmft}$ index (68.37\%). The mean $\mathrm{dmft}$ was 5.69 (SD 4.0). However, following excluding children with $(\mathrm{dmft}=0 ; \mathrm{n}=2,001)$, the mean $\mathrm{dmft}$ was raised to
6.41 (SD 3.65). In other words, the children who had not experienced dental caries were $11.18 \%$, and the caries prevalence was $88.82 \%$, indicating the proportion of the children who had one or more teeth decayed, missing due to caries, or filled.

When comparing children based on nationality (Table 2) the non-Saudi children ( $\mathrm{n}=4,122 ; 23.04 \%)$ showed slightly higher values compared with Saudi children ( $n=13,769,76.96 \%)$. However, statistically, there were only significant differences in values of $[\mathrm{dt}]$ mean, $\mathrm{dt}=0$, and $[\mathrm{ft}]$ mean $(\mathrm{p}<0.05)$ between Saudi and nonSaudi children.

Comparing children based on age levels is shown in Table 3. The mean [dt] for 6 to 7,7 to 8 , and 8- to 9-year-old groups were decreasing, 4.09 (SD 3.73), 3.93 (SD 3.34), 3.64 (SD 2.99) respectively. This was statistically significant $(\mathrm{p}<0.05)$. The $\mathrm{dmft}$ index was higher for the 7 - to 8-yearold children (5.81, SD 3.98) followed by the $\mathrm{dmft}$ for 8- to 9-year-old children (5.79, SD 3.79) and the dmft for 6- to 7 -year-old children (5.47, SD 4.18). However, there were no statistical significant differences $(p>0.05)$ between 7 to 8 and 8- to 9-year-old children. The 6- to 7-year-old children were statistically different from 7 to 8 and 8 - to 9-year-old children.

\section{DISCUSSION}

A number of caries prevalence surveys in Saudi Arabia have been conducted in different cities or regions. In Riyadh, the studies among elementary schoolchildren showed a continuous high prevalence of caries.

Table 2: Caries prevalence comparison based on nationality

\begin{tabular}{|c|c|c|c|c|c|c|c|c|}
\hline & \multicolumn{3}{|c|}{ The decayed teeth [dt] } & \multirow{2}{*}{$\begin{array}{l}\text { The missing } \\
\text { teeth due to } \\
\text { caries [mt] } \\
\text { Mean (SD) }\end{array}$} & \multirow[b]{2}{*}{$\begin{array}{l}\text { The filled } \\
\text { teeth [ft] } \\
\text { Mean (SD) }\end{array}$} & \multicolumn{3}{|c|}{ The [dmft] index } \\
\hline & Mean (SD) & $d t=0 n(\%)$ & $\begin{array}{l}\text { Mean }(S D) \\
\text { after excluding } \\
{[d t]=0}\end{array}$ & & & Mean (SD) & $d m f t=0 n(\%)$ & $\begin{array}{l}\text { Mean }(S D) \\
\text { after excluding } \\
{[\mathrm{dmft}]=0}\end{array}$ \\
\hline $\begin{array}{l}\text { Saudi } \\
\mathrm{n}=13,769\end{array}$ & $3.85(3.37)$ & $3,137(22.78 \%)$ & $4.98(3.01)$ & $1.39(2.20)$ & $0.42(1.07)$ & $5.66(3.99)$ & $1,572(11.42 \%)$ & $6.39(3.65)$ \\
\hline $\begin{array}{l}\text { non-Saudi } \\
n=4,122\end{array}$ & $4.03(3.40)$ & $822(19.94 \%)$ & $5.03(3.06)$ & $1.46(2.26)$ & $0.29(0.84)$ & $5.78(3.99)$ & $429(10.41 \%)$ & $6.45(3.66)$ \\
\hline p-value & $<0.05$ & $<0.05$ & $>0.05$ & $>0.05$ & $<0.05$ & $>0.05$ & $>0.05$ & $>0.05$ \\
\hline
\end{tabular}

Table 3: Caries prevalence comparisons based on age level

\begin{tabular}{|c|c|c|c|c|c|c|c|c|}
\hline & \multicolumn{3}{|c|}{ The decayed teeth [dt] } & \multirow{2}{*}{$\begin{array}{l}\text { The missing } \\
\text { teeth due to } \\
\text { caries [mt] } \\
\text { Mean (SD) }\end{array}$} & \multirow[b]{2}{*}{$\begin{array}{l}\text { The filled } \\
\text { teeth [ft] } \\
\text { Mean (SD) }\end{array}$} & \multicolumn{3}{|c|}{ The [dmft] index } \\
\hline & Mean (SD) & $d t=0 n(\%)$ & $\begin{array}{l}\text { Mean }(S D) \\
\text { after excluding } \\
{[d t]=0}\end{array}$ & & & Mean (SD) & $d m f t=0 n(\%)$ & $\begin{array}{l}\text { Mean }(S D) \\
\text { after excluding } \\
{[\mathrm{dmft}]=0}\end{array}$ \\
\hline $\begin{array}{l}6-7 \text { years } \\
(n=6,183)\end{array}$ & $4.09^{\mathrm{a}}(3.73)$ & $1,484(24.0 \%)^{d}$ & $5.38^{f}(3.37)$ & $1.06^{\mathrm{i}}(1.68)$ & $0.32^{\prime}(0.96)$ & $5.47^{n}(4.18)$ & $895(14.48 \%)^{p}$ & $6.40^{\mathrm{s}}(3.81)$ \\
\hline $\begin{array}{l}7-8 \text { years } \\
(\mathrm{n}=5,848)\end{array}$ & $3.93^{b}(3.34)$ & $1,251(21.39 \%)^{\mathrm{e}}$ & $5.0^{\mathrm{g}}(2.98)$ & $1.47^{\mathrm{j}}(2.17)$ & $0.41^{\mathrm{m}}(1.03)$ & $5.81^{\circ}(3.98)$ & $593(10.14 \%)^{\mathrm{q}}$ & $6.47^{\mathrm{s}}(3.66)$ \\
\hline $\begin{array}{l}8-9 \text { years } \\
(\mathrm{n}=5,860)\end{array}$ & $3.64^{\mathrm{c}}(2.99)$ & $1,224(20.89 \%)^{\mathrm{e}}$ & $4.60^{\mathrm{h}}(2.62)$ & $1.71^{\mathrm{k}}(2.65)$ & $0.45^{\mathrm{m}}(1.06)$ & $5.79^{\circ}(3.79)$ & $513(8.75 \%)^{r}$ & $6.34^{\mathrm{s}}(3.49)$ \\
\hline
\end{tabular}

Vertical: Same superscript letter $=$ no significant difference $(p>0.05)$. 
A survey in Riyadh by Al-Banyan et $\mathrm{al}^{8}$ showed a dmft value of 3.8 among 272 male and female children group aged 5 to 12 years. The caries prevalence $(\% \mathrm{dmft}>0)$ was very high reaching $99.3 \%$. Mansour et al conducted a survey in 2000 including only 200 female children of 6 to 7 years old. The resulting $\mathrm{dmft}$ was 7.0 and the caries prevalence was $95 \% .{ }^{9}$ In another study that included 449 children of 8 to 9 years old, the caries prevalence was $94 \%$ with a dmft value of 6.3. ${ }^{11}$

Al-Wazzan ${ }^{10}$ conducted a study in 2004 including 602 male and female children, aged 6 to 7 years. The prevalence of caries was $94.4 \%$ and the $\mathrm{dmft}$ was 7.34 for both male and female children. However, the $\mathrm{dmft}$ index for male children only was higher at 8.13 , while the $\mathrm{dmft}$ for female participants was 6.48 .

$\mathrm{Al}$ Dosari et $\mathrm{al}^{12}$ investigated the caries prevalence for children of 6 to 7 years old, and resulted in caries prevalence of $91.2 \%$ in both cities, and the $\mathrm{dmft}$ was 6.53 for Riyadh children group. These reports were with quite low sample sizes and showed very high caries prevalence and $\mathrm{dmft}$ values. Since then, there have been no recent or updated surveys. A literature review in 2013 by Al Agili $^{6}$ suggested the need for updating the baseline information regarding caries prevalence.

Comparison to previous studies would be difficult and challenging due to the variation in study design, populations examined, target groups, and sample size. However, as stated earlier, this survey was conducted to update the literature.

The present study, with this increased sample size, showed slight decrease in caries prevalence, but still high. The mean dmft for the children was 5.69, and 6.41 following excluding the caries-free $(\mathrm{dmft}=0)$ children. The caries prevalence $(\% \mathrm{dmft}>0)$ was $88.82 \%$. Many previous studies in Saudi among children have reported decay [dt] as the major component of $\mathrm{dmft}$ score. ${ }^{15-18}$ This is a similar finding in the current study in which the [dt] accounted for $68.37 \%$ of the $\mathrm{dmft}$ score.

The proportion of children with active caries was $77.87 \%$, and most of the decayed teeth were unrestored; children with at least one filling $(n=3,234 ; 18.08 \%)$. The children who had at least one missing tooth due to caries accounted for $49.86 \%$ of the examined children.

This would highlight the high prevalence of active, untreated caries with extraction being more a treatment of choice over fillings. Our results showed that the treatment provided, as determined by the filled [ft] and missing teeth due to caries [mt] teeth was low, accounting for only $31.63 \%$ of the $\mathrm{dmft}$ value. This is similar to the findings by Alamoudi et $\mathrm{al}^{19}$ and Farsi. ${ }^{20}$

This may be a reflection of poor dental awareness and lack of education in seeking treatment. In fact, our clinical experience shows that many patients seek treatment only when there are serious signs and symptoms.

In Saudi Arabia, male and female schools are separate, and it is not allowed for female investigators to access male students and schools according to Saudi community traditions. For this reason, this study involved only female students. The public schools are usually attended by children of low to middle socioeconomic class. However, investigating its effect on caries prevalence was not a scope of the current study.

With the limitation of this study regarding the examination setting, especially with regard to using natural light and class room chair, there is always concern about detecting proximal caries, and tooth-colored restoration and could be missed during our screening. ${ }^{21,22}$ This would result in underestimating the $\mathrm{dmft}$ values. ${ }^{4}$

This study supports the high prevalence of caries among children of this age group; 6 to 9 years for both Saudi and non-Saudi children in Riyadh. The limitation of this study includes our inability to investigate other factors contributing to caries like oral hygiene practices, sugar consumption, and attitude toward dental services. These factors along with the fluoride level in the water consumed by these children could have provided us with a thorough data regarding dental caries.

The differences between Saudi and non-Saudi children would highlight the different awareness about oral hygiene, life style, and cultural factors, giving greater attention to oral hygiene.

Although this study is based on visual inspection only without radiographs examination, this is often the only choice for many epidemiologic studies with acceptable sensitivity and specificity of the visual inspection for caries diagnosis. ${ }^{21,23,24}$

Surveys are used to monitor the trends in oral health and disease, develop policy, evaluate dental health programs, and assess the dental needs. ${ }^{4,5}$ This study has provided useful baseline data for future comparisons. The caries prevalence information would assist in the determination of treatment needs and preventive efforts, planning programs, formulation of appropriate strategies, and to be used in the future for the design of oral health education programs for this specific age group. With these results, there is a need for immediate attention facilitating the dental access, making referrals to these students, and making their parents more aware of the existing problems.

\section{CONCLUSION}

The dental caries prevalence among the study population was high, with majority of children having untreated caries. 
The results will be useful for comparison with future research both in this country and the Eastern Mediterranean Region.

They also highlight the need for initiating deliberate community-based preventive measures for improvement in public health education and services provided for the prevention, early detection, and treatment of dental caries for all children.

\section{ACKNOWLEDGMENT}

Authors would like to thank the teachers for their cooperation and to the field examiners for their great efforts.

\section{REFERENCES}

1. Kassebaum NJ, Bernabé E, Dahiya M, Bhandari B, Murray CJL, Marcenes W. Global burden of untreated caries: a systematic review and metaregression. J Dent Res 2015 May;94(5): 650-658.

2. Marcenes W, Kassebaum NJ, BernabéE, Flaxman A, Naghavi M, Lopez A, Murray CJ. Global burden of oral conditions in 19902010: a systematic analysis. J Dent Res 2013 Jul;92(7):592-597.

3. Burt BA. How useful are cross-sectional data from surveys of dental caries? Community Dent Oral Epidemiol 1997 Feb;25(1):36-41.

4. Jain SK, Pushpanjali K, Reddy SK, Gaikwad R, Deolia S. Comparison of different caries diagnostic thresholds under epidemiological and clinical settings among 7-15 year old school children from Bangalore city. J Int Soc Prev Community Dent 2013 Jul-Dec;3(2):85-91.

5. Kassawara ABC, Assaf AV, Meneghim Mde C, Pereira AC, Topping G, Levin K, Ambrosano GM. Comparison of epidemiological evaluations under different caries diagnostic thresholds. Oral Health Prev Dent 2007;5(2):137-144.

6. Al Agili DE. A systematic review of population-based dental caries studies among children in Saudi Arabia. Saudi Dent J 2013 Jan;25(1):3-11.

7. Al-Ansari AA. Prevalence, severity, and secular trends of dental caries among various Saudi populations: a literature review. Saudi J Med Med Sci 2014 Oct;2(3):142-150.

8. Al-Banyan RA, Echeverri EA, Narendran S, Keene HJ. Oral health survey of 5-12-year-old children of National Guard employees in Riyadh, Saudi Arabia. Int J Paediatr Dent 2000 Mar;10(1):39-45.

9. Mansour M, Anwar S, Pine C. Comparison of caries in 6-7 year old Saudi girls attending public and armed forces schools in Riyadh, Saudi Arabia. Saudi Dent J 2000;12(1):33-36.
10. Al-Wazzan KA. Dental caries prevalence in 6-7 year-old school children in Riyadh region: a comparative study with the 1987 Oral Health Survey of Saudi Arabia Phase I. Saudi Dent J 2004 May-Aug;16(2):54-60.

11. Wyne A, Al-Ghorabi B, Al-Asiri Y, Khan NB. Caries prevalence in Saudi primary schoolchildren of Riyadh and their teachers' oral health knowledge, attitudes, and practices. Saudi Med J 2002 Jan;23(1):77-81.

12. Al Dosari AM, Wyne AH, Akpata ES, Khan NB. Caries prevalence and its relation to water fluoride levels among schoolchildren in Central Province of Saudi Arabia. Int Dent J 2004 Dec;54(6):424-428.

13. Statistical and Information Technology Department. Ministry of Education, KSA. 1436-1437 H (Personal Communication).

14. World Health Organization. Oral health surveys: basic methods. 5th ed. Geneva: WHO Publications; 2013.

15. Khan NB, Al Ghannam NA, Al Shammery AR, Wyne AH. Caries in primary school children: prevalence, severity and pattern in Al-Ahsa, Saudi Arabia. Saudi Dent J 2001 MayAug;13(2):71-74.

16. Al-Sekait MA, Al-Nasser AN. Dental caries prevalence in primary Saudi schoolchildren in Riyadh district. Saudi Med J 1988;9(6):606-609.

17. Al-Shammery AR, Guile EE, EI-Backly M. Prevalence of caries in primary school children in Saudi Arabia. Community Dent Oral Epidemiol 1990 Dec;18(6):320-321.

18. Akpata ES, al-Shammery AR, Saeed HI. Dental caries, sugar consumption and restorative dental care in 12-13-year-old children in Riyadh, Saudi Arabia. Community Dent Oral Epidemiol. 1992 Dec;20(6):343-6.

19. Alamoudi N, Salako NO, Massoud I. Caries experience of children aged 6--9 years in Jeddah, Saudi Arabia. Int J Paediatr Dent 1996 Jun;6(2):101-105.

20. Farsi N. Developmental enamel defects and their association with dental caries in preschoolers in Jeddah, Saudi Arabia. Oral Health Prev Dent 2010 Jan;8(1):85-92.

21. Weyant RJ, Manz M, Corby P. Dental caries status and need for dental treatment of Pennsylvania public school children in grades 1,3, 9, and 11. J Public Health Dent 2004Sep;64(3):136-144.

22. Beltrán ED, Malvitz DM, Eklund SA. Validity of two methods for assessing oral health status of populations. J Public Health Dent 1997 Fall;57(4):206-214.

23. Kidd EA, Ricketts DN, Pitts NB. Occlusal caries diagnosis: a changing challenge for clinicians and epidemiologists. J Dent 1993 Dec;21(6):323-331.

24. Ketley CE, Holt RD. Visual and radiographic diagnosis of occlusal caries in first permanent molars and in second primary molars. Br Dent J 1993 May;174(10):364-370. 